\title{
ESTRUCTURA ORGANIZATIVA E IMAGEN PROMOCIONAL DEL CAMINO DE SANTIAGO
}

\author{
Antón Álvarez Sousa \\ Alfonso Gomis Rodríguez \\ Miguel Ángel Gallego Valiña'
}

Universidade da Coruña

\begin{abstract}
Resumen: Se analiza la promoción del Camino de Santiago en las últimas décadas, el contexto en que se hizo, los actores que intervinieron en el proceso, las estrategias de promoción para atraer a turistas y a intermediarios, el patrocinio, la colaboración con el sector privado, con las instituciones políticas, con los medios de comunicación y con la sociedad civil; las acciones de comunicación realizadas, los materiales empleados con sus símbolos de identidad (mascota, logotipos, credenciales), los cambios de imagen bajo la marca Xacobeo, y la correspondencia entre comunicación realizada (imagen proyectada), la imagen conformada previa, y la imagen percibida a posteriori por los visitantes.
\end{abstract}

Palabras clave: Camino de Santiago, imagen turística, promoción, destino turístico, peregrinación, Xacobeo, patrocinio, logotipo.

Resumo: Estructura organizativa e imaxe promocional do Camiño de Santiago Analízase a promoción do Camiño de Santiago nas últimas décadas, o contexto en que se fixo, os actores que interviñeron no proceso, as estratexias de promoción para atraer turistas e intermediarios, o patrocinio, a colaboración co sector privado, coas institucións políticas, cos medios de comunicación e coa sociedade civil; as accións de comunicación realizadas, os materiais empregados cos seus símbolos de identidade (mascota, logotipos, credenciais), os cambios de imaxe baixo a marca Xacobeo, e a correspondencia entre comunicación realizada (imaxe proxectada), a imaxe conformada previa e a imaxe percibida a posteriori polos visitantes.

Palabras clave: Camiño de Santiago, imaxe turística, promoción, destino turístico, peregrinación, Xacobeo, patrocinio, logotipo.

Abstract: Organisational structure and promotional image of the Camino de Santiago (The Way of St James)

1 Antón Álvarez Sousa: sousa@udc.es; Alfonso Gomis Rodríguez: agomis@udc.es; Miguel Ángel Gallego Valiña:mgv@hotmail.com 
This includes an analysis of the promotion of the Camino de Santiago over the last few decades, the context in which this was carried out, the parties involved in the process, the promotional strategies to attract tourists and travel agencies, sponsorship, and collaboration with the private sector, with the political institutions, with the media and with civil society. It also examines the communication activities carried out, the materials used with their identifying symbols (mascot, logotype, credentials), the changes of image under the Xacobeo brand, and the link between the communication carried out (image projected), the confirmed initial image and the a posteriori image perceived by visitors.

Key words: Camino de Santiago, tourist image, promotion, tourist destination, pilgrimage, Xacobeo, sponsorship, logotype.

\section{INTRODUCCIÓN}

Si existe un sector de servicios en el que la promoción es importante, en el turismo se eleva hasta el nivel que a veces la propia promoción se convierte en la acción que conforma dicho producto. Ello es así debido a que en el turismo muchas veces se trata de darle un nuevo significado a una serie de elementos-fenómenos materiales o inmateriales, naturales o culturales, que han de servir de núcleo del producto turístico.

En este artículo analizamos las acciones realizadas para la promoción del Camino de Santiago en las últimas décadas del siglo XX que lo llevaron a transformarse en un producto turístico bajo la marca Xacobeo, con logotipos y mascotas específicas. Analizaremos las acciones de comunicación llevadas a cabo, los materiales utilizados y los cambios experimentados en los símbolos para adaptarse constantemente.

Todo este proceso no se puede entender descontextualizado, sino que es necesario entenderlo dentro de las coordenadas espacio-temporales. Como dice Mills (1987), no podemos entender un fenómeno sin entender la sociedad donde se produce y a su vez cual fue la trayectoria de ese fenómeno a lo largo del tiempo-Camino de Santiago hasta llegar al Xacobeo- y la relación de esa sociedad con otras -peregrinación a Santiago en relación con otros centros de peregrinación y los centros emisores de peregrinos-turistas.

Por lo dicho, las partes que incluiremos en nuestro análisis para entender la promoción del Camino de Santiago desde Galicia son las siguientes:

- El contexto de la promoción del Camino de Santiago.

- Los actores que intervienen en el proceso de promoción

- Las acciones de comunicación realizadas

- Los materiales empleados con sus símbolos de identidad: mascota, logotipos, credenciales...

- Los cambios de imagen planificados: para el Xacobeo de 1993, de 1999, de 2004 y del futuro (2010)

- A modo de conclusión: correspondencia entre comunicación realizada (imagen proyectada) - realidad turística - imagen conformada previa imagen percibida a posteriori. 


\section{EL CONTEXTO DE LA PROMOCIÓN DEL CAMINO DE SANTIAGO}

La peregrinación a Santiago de Compostela es equiparable dentro de la Cristiandad a otros dos grandes centros de peregrinación: Roma y Jerusalén. La peregrinación a estos otros dos lugares Santos no se había descuidado durante el siglo XX como en el caso de Santiago de Compostela. En Santiago comenzó a recuperarse la importancia que había tenido siglos atrás a partir del año 1982, y enfocado al turismo a partir del Xacobeo de 1993, si bien la promoción comenzó dos años antes.

Con Juan Pablo II como Papa que amaba el viaje a distintos lugares de la tierra, el arzobispo de Santiago, Monseñor Rouco Varela, se propone traerlo de peregrinación a Santiago y realiza las gestiones que culminan con el viaje en el año 1982. Este es sin lugar a dudas el año del despegue de la peregrinación a Santiago. Unos años más tarde repetiría el viaje para tener un encuentro en este caso con un sector específico: los jóvenes del mundo. El lugar del encuentro sería más tarde el símbolo de la llegada a Santiago: “O Monte do Gozo". Allí se acondicionaría hospedaje para peregrinos, gran coliseum al aire libre y centro de conciertos, metas de vuelta ciclista, etc.

En la década de los ochenta del siglo XX también es el momento en que se están conformando las estructuras autonómicas españolas -entre ellas la gallega- que asumirían las competencias en materia de turismo, reservándose a la administración nacional la promoción en el extranjero - que compartirá de hecho con las acciones de promoción desde las autonomías. Esto tendrá una gran repercusión en el desarrollo turístico de todas las autonomías.

Un tercer factor es que estas fechas coinciden con el momento en que los españoles elevan su nivel y calidad de vida y España deja de ser fundamentalmente un centro receptor de turismo para ser también un centro emisor de turistas. A partir de ese momento la mayoría de los ciudadanos tendrán acceso al turismo y una gran parte de los que no pueden por falta de recursos económicos, podrán acogerse a los programas de turismo social. Santiago de Compostela se promocionó en todos los rincones de España y para cualquier español la visita a Santiago se convirtió en algo casi obligado socialmente.

Un cuarto factor es que el turismo de sol y playa necesita ser complementado con otros tipos de turismo, tal y como se dice en el informe de la situación del turismo en España encargado por Turespaña a principios de la década de los noventa. Así se buscan turismos alternativos que complementen la oferta turística tradicional y se pretende con ello dar una nueva identidad y orientación al turismo español que se había centrado en las zonas de costa, fundamentalmente del Mediterráneo y en el turismo de las tres $\mathrm{S}$.

Ya en la década de los ochenta, en Santiago de Compostela se habían realizado las gestiones necesarias para obtener el máximo distintivo cultural de patrimonio y a mediados de la década se consigue que la UNESCO le otorgue el distintivo de Patrimonio de la Humanidad a su casco histórico. Este distintivo se vería incrementado 
cuando a principios de la década de los noventa se le concede, ya con el programa Xacobeo en marcha, el mismo distintivo para el Camino de Santiago, del que se beneficiarán los distintos municipios por donde transcurre el Camino Francés.

En este ambiente, a principios de la década de los noventa, Barcelona se convierte en la sede de los Juegos Olímpicos y Sevilla de la exposición mundial (Expo 92). Ambos centros pretenden aprovechar estos acontecimientos para dar un cambio y convertirse en centros de atracción turística de primera magnitud. Es decir, Juegos Olímpicos y Expo serían el comienzo del gran despegue turístico de Cataluña y Andalucía. Al igual que estas Comunidades Autónomas, y las ciudades que eran centros de la dinámica político-administrativa de las regiones, en Galicia se busca un nuevo elemento que sirva de atracción turística, un elemento que constituya el núcleo de un gran producto turístico y se propone que sea Santiago de Compostela y el Camino de Santiago. Desde el Gobierno Central se acepta de modo excelente, sobre todo porque la propuesta que aunque en principio parece que necesita de un gran presupuesto, es mucho menor que la inversión de Barcelona o Sevilla.

Además, en el ánimo de que se aprovechasen los esfuerzos de Barcelona y Sevilla -considerados más importantes por los gobernantes gallegos- los políticos consideraban adecuado que se adelantase el Año Santo de 1993 a 1992. Se lo propusieron al Arzobispo y éste lo rechaza, diciendo que debe de primar la "autenticidad" de la peregrinación sobre los acontecimientos de masas deportivos, ferias o de cualquier otra naturaleza externos a la tradición jacobea. Esto fue sin duda un acierto, pues en dicho caso se perdería el bien más preciado del producto turístico jacobeo: autenticidad y tradición.

Parece que la lógica del Arzobispo tenía razón sobre la de los políticos: el Año Santo de 1993 se celebró con éxito y continuó a lo largo de los años -1994, 2004 y se espera que en el 2010- cosa que no ocurrió con los otros acontecimientos señalados.

Resumiendo, los factores que sirvieron de despegue y promoción del Camino de Santiago a finales del siglo XX fueron:

- $\quad$ La misión que en la Iglesia Católica significó la actividad de Juan Pablo II y su peregrinación a Santiago de Compostela en el 1982 y posteriormente: viaje de personajes ilustres

- La nueva orientación del turismo en España que pasa de ser un turismo de sol y playa a un turismo cultural: diversificación turística

- El desarrollo de las autonomías y las competencias en turismo, intentando buscar las posibilidades de desarrollo a través del acondicionamiento y promoción de los recursos-productos más importantes: sinergias del capital social-institucional

- La elevación del nivel de vida de los españoles que los convierte en viajeros e intentan recuperar sus tradiciones: paso de la sociedad tradicional y el estilo de vida del ahorro a la sociedad del ocio y el consumo conspicuo. 


\section{LOS ACTORES DE LA PROMOCIÓN DEL CAMINO DE SANTIAGO. EL CAPITAL SOCIAL}

La promoción del Camino de Santiago es algo que se viene realizando desde hace muchos siglos y se contó con la intervención de múltiples actores, que van desde emperadores y papas hasta los humildes peregrinos que realizaron el Camino y lo difundieron en sus lugares de origen o de paso.

Los actores que contribuyeron a la transformación del Camino de Santiago en un producto turístico de primera magnitud con renombre mundial fueron muchos, pero es necesario destacar por una parte las organizaciones y por otra los particulares. Entre las organizaciones que contribuyeron a promocionar el Camino de Santiago tenemos que señalar las de origen civil, político y religioso. Entre los particulares tenemos que indicar las personas que hacen el camino desde el anonimato y aquellas otras que lo hacen desde su condición de personas ilustres o de personas que escribieron sobre el camino o realizaron alguna otra acción que dejaron su impronta.

Es decir, para que se produzca una promoción del turismo, y en concreto del Camino de Santiago, que vaya más allá que un mero acto individual y puntual en el tiempo, y se convierta en que la promoción es un acto de todos y que se prolonga de forma intemporal, se necesita previamente la creación de un capital social: conjunto de personas, de instituciones, empresas y organizaciones de distinto tipo que aúnan sus esfuerzos para contribuir a una causa.

Prueba de la importancia de este plan fue que en el año 1993 atrajo a Santiago de Compostela en torno a los diez millones de visitantes, de los cuales hicieron el Camino a pie, en bicicleta o a caballo 1.541.747 según los datos que constan en los lugares por donde transitan y tienen que mostrar sus credenciales. En el año 1999 se volvió a repetir la gran afluencia con un total de once millones de visitantes y el año 2004 volvió a ser otra vez un éxito. Estos datos nos avalan para considerarlo un importante plan turístico que sólo fue posible gracias a la promoción y colaboración de diversos actores que se pueden medir por la densidad institucional

Todas estas formas de capital social se pueden analizar conjuntamente desde la perspectiva de la sinergia. Creo que el autor que mejor desarrolló fue Peter Evans (1997), quien considera que la acción de las instituciones del gobierno, de las empresas y las de los ciudadanos si se realiza de forma conjunta puede dar lugar a una sinergia muy superior a la que daría la suma de cada una de ellas por aislado.

Como asociaciones de base en torno al Camino de Santiago tenemos que recurrir a un amplio número de asociaciones -de carácter civil o eclesiástico- que surgieron a partir de mediados del siglo XX. Las primeras fueron la "Asociación de Amigos del Camino" de París -1950- y posteriormente la de Estella. ${ }^{2}$ Después, a partir

2 En todo caso, las actuales asociaciones tienen un cierto origen-paralelismo con las cofradías del Apóstol Santiago de las que tenemos noticias desde el siglo XII (Rodríguez, 1996). Estas cofradías tenían fines de asistencia espiritual, física-intendencia (hospitalarias) para realizar el Camino y guerrero para defender a las poblaciones de posibles ataques. 
de 1982 con la venida del Papa a Santiago de Compostela y ya finalmente a partir de 1993 con la organización del Xacobeo, asistimos a una gran proliferación de asociaciones en torno al Camino de Santiago. Estas asociaciones, fundadas por personas que habían compartido la experiencia de realizar el Camino conjuntamente, o bien por personas que no lo habían realizado pero que se juntaron para realizarlo, llevan a cabo distintas acciones: dar a conocer el camino, recuperar tramos del camino, preparar a las personas física y espiritualmente para realizarlo, etc. En el año 1987 se propone la creación de una Federación de Asociaciones que coordinase las actividades de las distintas asociaciones. La proliferación de asociaciones de distinto ámbito -parroquial, municipal, provincial, regional, interregional, nacional, internacional, etc.- a partir de esos momentos fue enorme. De forma paralela a estas asociaciones siguen subsistiendo las cofradías en torno al Apóstol Santiago que están extendidas por distintos países de Europa. A estas asociaciones hay que sumar otras que surgieron durante la década de los noventa del siglo $\mathrm{XX}$, las cuales tienen como finalidad fundamental aglutinar intereses de distintas administraciones para conseguir fondos e impulsar así el camino de Santiago y coordinar las distintas actividades oficiales a seguir (LEIRA LÓPEZ, 1999; GARCIA-ABRIL, 1999).

\section{ASOCIACIONES DEL CAMINO DE SANTIAGO}

Tipo de Objetivos Actividades

asociaciones

Nivel primario:

Fomentar la peregrinación a Santiago de Compostela y asistir-orientar al peregrino
- Socializar a los peregrinos y prepararles física y espiritualmente para realizar el camino

- Organizar las peregrinaciones

- Distribuir y controlar las credenciales de peregrino

- Asistirles en los albergues y en las necesidades a lo largo del camino

Trabajar por la conservación, defensa y revitalización del Camino
- Señalización del Camino

- Promoción de los itinerarios menos conocidos

- Creación de albergues y centros de acogida.
Fomentar los estudios y publicaciones sobre el Camino
- Fomentar la creación de equipos que se dediquen a esta labor

- Estudios de itinerarios que no son bien conocidos para luego activarlos.

- Traspasar información de unas asociaciones e instituciones a otras.

- Realizar investigaciones en profundidad sobre temas específicos del Camino (siendo fundamental la colaboración con las Universidades)

- Publicaciones sobre el Camino de Santiago.

- Organización de jornadas y congresos para realizar exposiciones y debates sobre el tema 


\section{ASOCIACIONES DEL CAMINO DE SANTIAGO}

Nivel

institucional
La "Dirección Xeral de Promoción do Camiño"
Se creó en diciembre de 1993, dependiente de la Consellería de Cultura y se dedicó fundamentalmente a la promoción del Xacobeo
La S.A. de Xestión do Xacobeo
Es una empresa pública con un Consejo de Administración en el que están presentes representantes de distintas Consellerías y puso en funcionamiento múltiples proyectos para los que se necesitó importantes sumas de dinero del que damos cuenta en el apartado del capital financiero.

Consejo Xacobeo

Dependiente del Ministerio de Cultura, coordina las iniciativas y distribuye los medios económicos entre las Comunidades Autónomas por las que transcurre el Camino

Real Patronato de la Ciudad Presidido por el Rey, cuenta con la colaboración de de Santiago las tres administraciones (local, autonómica y nacional) representadas por el Alcalde de la Ciudad de Santiago y los Presidentes del Gobierno Español y Autonómico.

\begin{tabular}{lll}
\cline { 2 - 3 } $\begin{array}{l}\text { Consorcio de Santiago } \\
\text { Nivel }\end{array}$ & Órgano ejecutivo del Real Patronato \\
\hline $\begin{array}{l}\text { Relaciones entre asociaciones } \\
\text { del Camino de Santiago de } \\
\text { distinto tipo }\end{array}$ & $\begin{array}{l}- \text { Entre asociaciones dedicadas al estudio y a la } \\
\text { promoción del Camino y a la asistencia de pe- } \\
\text { regrinos }\end{array}$ \\
& $\begin{array}{l}\text { - Entre asociaciones religiosas y asociaciones ci- } \\
\text { viles e institucionales }\end{array}$ \\
\cline { 2 - 3 } $\begin{array}{l}\text { Relaciones entre asociaciones } \\
\text { de peregrinaciones de distin- } \\
\text { tas partes del mundo }\end{array}$ & $\begin{array}{l}\text { - Puesta de acuerdo sobre fines espirituales en } \\
\text { todo tipo de personas y partes del mundo cris- } \\
\end{array}$ \\
& $\begin{array}{l}\text { tiano. } \\
\text { tipo de religión }\end{array}$ \\
& - Realización de acuerdos internacionales. \\
& - Realización de congresos y publicaciones.
\end{tabular}

Fuente: Elaboración propia a partir de Leira López, J., "As Asociacións de Amigos do Camiño de Santiago. O seu discurso social", en Antón Álvarez Sousa (dir.), Homo Peregrinus, Vigo, Xerais, 1999, pp. 129-152 y en García-Abril, G., "Evanxelización e promoción turística nas peregrinacións a Santiago", en Antón Álvarez Sousa (dir.), Homo Peregrinus, Vigo, Xerais, 1999, pp. 153-175. 
Además de estas asociaciones se formaron otras de carácter general entre los distintos mandatarios de los municipios por los que transcurre el Camino. También se formaron asociaciones entre empresarios que tenían intereses comunes, etc.

Pero dentro del capital institucional no sólo hay que dar cuenta del capital social formal, sino que también se dio un gran enriquecimiento del capital social informal -que sin duda está relacionado con otros como el simbólico- entre el que queremos destacar el "Día de las Instituciones" en el que se invitó a las autoridades de otras Comunidades Autónomas españolas y regiones francesas representadas normalmente por sus presidentes.

En suma, se dio un gran enriquecimiento del capital social en sus distintos aspectos, sectores y ámbitos que conllevaron a una unión de personas e instituciones que promocionaron el Camino de Santiago.

No todos los actores tienen el mismo interés a la hora de promocionar el Camino de Santiago. Podemos diferenciar distintos intereses según los distintos actores que darán como resultado diferentes concepciones del Camino. Tres son los grandes ejes que se pueden diferenciar: Públicos-privados, Laicos-religiosos, Organizacionales-particulares

La mayor parte de la promoción del Camino de Santiago fue realizada desde los actores públicos, quedando sólo un pequeño espacio para las empresas privadas, bien sean hoteles, restaurantes, empresas de transportes o de ocio que lo promocionaron como recurso para atraer clientes a sus negocios.

Aunque a partir del año 1991 la promoción laica asume el papel más importante, sobre todo por la gran cantidad de medios con que se contó por parte de las instituciones políticas, no cabe duda que fue en el año 1982 con la venida del Papa a Santiago de Compostela cuando se comienza con la gran promoción del Camino de Santiago.

Aunque las organizaciones de distinto tamaño -que van desde la Iglesia y las instituciones políticas a las pequeñas asociaciones, pasando por las redes de asociaciones- son las principales promotoras, también tenemos que contar con la importancia de los particulares que hicieron el Camino y lo transmitieron a su entorno bien mediante la boca a boca o bien mediante documentos de distinto tipo.

\section{ESTRATEGIA PROMOCIONAL PARA ATRAER A TURISTAS Y A INTER- MEDIARIOS}

\subsection{MARCO DE PARTIDA}

\subsubsection{ESTRATEGIAS COMUNICATIVAS}

Al realizar la promoción turística, dependiendo del tipo de estructura de la oferta, nosotros podemos adoptar dos estrategias diferentes (EJARQUE, 2005, pp. 232-234): 
A) Intentar llegar directamente al turista-consumidor, con un doble objetivo:

- Convencerle para que elija nuestro destino de vacaciones

- Que reserve y adquiera los servicios directamente o a través de intermediarios pero nunca proporcionados por nosotros

B) Las relaciones de promoción del destino se realizan fundamentalmente a través de intermediarios, actuando fundamentalmente sobre los que hacen las ventas: touroperadores y agencias de viajes. En este caso se trata de mantener relaciones estables y periódicas con las responsables de ventas de las empresas para darles la máxima información y apoyo.

La segunda opción es más típica de los destinos de turismo masificado de sol y playa que de otros destino como los culturales, aunque también existen algunos destinos culturales que optaron por esta opción.

En el caso del Xacobeo se optó por una opción mixta pero con predominio de la primera opción, siendo el propósito que el Camino de Santiago y sobre todo Santiago de Compostela fuese conocido en todo el mundo, que se motivase por visitarlo y que buscase personalmente la forma de viajar, ofreciendo incluso alojamiento e infraestructuras gratuitas para aquellos que se dignaban a hacerlo siguiendo sistemas tradicionales que le imprimirían identidad y servirían para conservar la autenticidad de antaño.

Esto no quiere decir que se olvidase la segunda forma de promoción, realizándose así una importante actividad para que los TTOO y las agencias de viajes se interesasen por ofrecer Santiago de Compostela como destino. Así se consiguió que a Santiago viajasen personas de todos los rincones del Planeta que van desde Europa a América o a Japón.

A su vez podemos diferenciar dos grandes tipos de medios para dar a conocer un destino que si bien se complementan, en la situación actual son bien diferentes y conllevan dos enfoques distintos:

A) La publicidad

- La publicidad a través de los medios de comunicación de masas, siendo el fundamental la televisión. Los que se deciden por centrar los recursos en esta opción consideran que el comportamiento de las personas en la sociedad actual está muy influenciado por lo que transmiten los medios de comunicación y se gastan unas sumas muy elevadas en ella.

- La publicidad a través del patrocinio, fundamentalmente de acontecimientos que mueven a muchas personas como son los deportivos: fútbol, ciclismo, conciertos, encuentros culturales, etc

- Publicidad en vallas publicitarias y otros lugares habilitados para ello

- Publicidad a través de otros medios: fuselajes de aviones, adhesivos en paredes, pavimentos, tarjetas de entradas a espectáculos, etc. 
B) Los contactos personales que se pueden realizar en distintos lugares y de distintos modos como son:
a. Ferias
b. Actuaciones educacionales
c. Relaciones públicas:
i. Con periodistas
ii. Con instituciones
iii. Con personajes ilustres
iv. Con productores de películas y documentales

A estos dos grandes medios en la actualidad se sumó Internet que sirve tanto para hacer publicidad de masas como para contactar entre personas con intereses similares.

\subsubsection{MATERIALES:}

Los materiales empleados para la promoción son de distinto tipo, siendo necesario en todo caso elaborar unos símbolos de identidad que han de estar presentes en toda la comunicación para que sirva de recuerdo al que lo ve. Son las señas de identidad: Logotipos, Mascotas

Medios materiales y soportes: Folletos, Guías turísticas, Pins, Documentales, Libros, Etc.

\subsection{ACTUACIONES}

El año santo compostelano de 1993 fue el primero en ser intensamente promocionado por parte de las instituciones autonómicas conscientes de la gran trascendencia, incidencia y potencialidad que el evento representaba para la revitalización y dinamización de toda Galicia. Por ello, y tras un exhaustivo análisis de las necesidades y posibilidades de actuación, se elaboró por primera vez un plan para la planificación y gestión integral Plan Xacobeo 93, aprobado por unanimidad por el parlamento gallego en junio de 1991. Uno de los grandes objetivos del Plan Xacobeo 93 fue la promoción exterior de Galicia con el objetivo de comunicar una nueva imagen de país "en pleno desarrollo, que mira al siglo XXI, pero que cuenta con un impresionante patrimonio cultural y artístico" (XUNTA DE GALICIA, 1994, p. 100), tratando de este modo de romper con la antigua imagen y estereotipos de territorio aislado y atrasado respecto del resto de España.

A partir de esta premisa inicial, la sociedad creada para la gestión del Xacobeo ha venido desempeñando con cada año jubilar, una labor de comunicación para dar a conocer toda la amplia gama de eventos y actividades que tienen lugar con motivo del año santo, la cual ha ido incrementándose y volviéndose cada vez más intensa.

En general, las tareas de promoción del Xacobeo se centran en la asistencia a ferias, el patrocinio de actividades deportivas, la presencia en actos culturales e institucionales, así como en la colaboración con otros entes y organismos. A continuación se analizan en detalle las actuaciones realizadas para la difusión del Xa- 
cobeo en sus ediciones de 1993, 1999 y 2004; en función de las distintas técnicas de comunicación empleadas. Pasamos a explicar las distintas acciones comunicativas empleadas como fueron las ferias y exposiciones, el patrocinio de eventos, la comunicación institucional, etc.

\subsubsection{FERIAS Y EXPOSICIONES}

Las ferias y exposiciones constituyen una forma de presentación periódica y de duración limitada de un producto para profesionales de un sector, intermediarios y clientes potenciales. Su objetivo es el de aprovechar la presencia del público para promocionarse, con la ventaja de poder establecer un contacto personal con cada uno de los diferentes colectivos implicados.

Las ferias de carácter profesional y especializado tienen un contenido comercial mucho más alto que el de las ferias generales abiertas al público ya que los aspectos promociónales, de imagen y de información se combinan, en distinto grado, con el enfoque comercial. En ellas se tiene la posibilidad de reunirse con intermediarios del sector y miembros del público para promocionarse turisticamente. Los organismos del destino elaboran diversas publicaciones que distribuyen entre los miembros del sector y los consumidores potenciales que solicitan información. Los catálogos suelen recoger las principales atracciones y actividades, mientras que los manuales para profesionales ofrecen una información para los intermediarios, sirviendo como guía de referencia (BIGNE ALCAÑIZ et al, 2000, pp. 67-68) .

El Xacobeo ha acudido con asiduidad a lo largo de los últimos años a numerosas ferias y exposiciones con el objetivo de promocionarse turisticamente. Las diferentes iniciativas de tipo promocional fuera de Galicia se han centrado fundamentalmente en el diseño de diversas exposiciones promocionales, de carácter itinerante, que permitan dar a conocer en todo el mundo la figura del Apóstol Santiago y del Año Santo, así como otros aspectos concretos de la programación del Xacobeo y del atractivo turístico de Galicia.

Ya en 1992, el Plan Xacobeo para el año siguiente establecía la participación por primera vez en ferias como la de FITUR (Feria Internacional de Turismo) en Madrid o el Pabellón de Galicia en la Exposición Universal de Sevilla que sirvieron de escaparate internacional del gran acontecimiento que se estaba proyectando para Galicia. En 1993 se acudió de nuevo a FITUR así como a las demás principales ferias de turismo de nuestro país como fueron Expocio también en Madrid, el II Salón del Turismo de Cataluña en Barcelona, Expovacaciones en Bilbao y Turisport en Silleda (Pontevedra); aunque también fuera de nuestras fronteras como en el caso de la Semana Verde de Berlín.

Asimismo, con motivo del Año Santo de 1993 también se organizaron congresos y reuniones con operadores turísticos internacionales tanto dentro como fuera de Galicia. Mención especial merece en ese año la reunión celebrada en la isla de La Toja (Pontevedra) con agentes de viaje de Latinoamérica y que reunió a más de trescientos cincuenta profesionales del sector. 
En 1999, la participación en las principales ferias de turismo de carácter nacional e internacional y la organización de exposiciones promocionales volvió a ser de nuevo una de las principales estrategias de difusión del Xacobeo, destinadas tanto a colectivos profesionales del sector como al público general. Esta labor de difusión comenzó en el verano de 1998 con la muestra Lisboa-Santiago. La espiritualidad y la peregrinación jacobeas celebrada durante la Exposición Universal de la capital portuguesa y que luego recorrió otras ciudades del país con un total de más de 150.000 visitantes. Otras exposiciones organizadas fueron Huellas Jacobeas que recorrió en colaboración con el Ministerio de Asuntos Exteriores y el Instituto Cervantes numerosas ciudades de Europa e Hispanoamérica; la muestra fotográfica Xacobeo 99 que estuvo presente en numerosos espacios con una gran concurrencia de público como aeropuertos y áreas comerciales, así como en diferentes Centros Gallegos de todo el mundo; y la exposición Galicia. Presencias y esencias de una cultura, instalada ya desde 1995 en el Pabellón de Galicia en Santiago con carácter permanente a fin de proporcionar información actualizada sobre el Xacobeo y la capital compostelana.

Madrid, Barcelona, Bilbao o Berlín, así como otras ciudades como Lisboa, Milán, París, Roma o Londres; contaron de nuevo con un stand del Xacobeo en sus ferias de turismo dedicado exclusivamente a la promoción del Camino de Santiago. De igual manera, durante 1998 y 1999, se llevaron a cabo múltiples presentaciones del Xacobeo como producto para agentes de viajes y touroperadores de toda España y Portugal. El valor añadido que el Camino tiene para Galicia y el conjunto de España como destino turístico justificó la presencia del Xacobeo en todas estas reuniones.

A lo largo de 2004, la presencia del Xacobeo en ferias se multiplicó estando representada dentro de la comunidad gallega en Turisport (Silleda), Expogalaecia (Vigo), Fimo (Ferrol), Gastronomía y turismo (Ourense), Fexdega (Vilagarcía), Forum-Ensino (Ourense) y Ferpalia (Pontevedra); y en el resto de Españas de nuevo en FITUR, SIT (Barcelona) y Expovacaciones (Bilbao), Agroturismo (León), Turicom (Gijón) e Intur (Valladolid); además de participar en diferentes muestras multisectoriales en distintos puntos del país. En el extranjero, se instalaron stands del Xacobeo en ferias internacionales como las de Vakantiebeurs Utrech, CMT Stuttgart, MIT Milán, Salón Mundial de París, Salon des Vacances de Bruselas, STEPS, WRM de Londres, Resiemarkt en Colonio, ABAV-Brasil, Turismo de Berlín y BTL en Lisboa.

De nuevo el Instituto Cervantes colaboró en la difusión del Xacobeo mediante la muestra Camino de Santiago. Luz y vida, inaugurada en octubre de 2003 en Viena y que recorrió durante todo el Año Santo numerosas ciudades europeas con el fin de acercar al público la cultura jacobea. Otras exposiciones fueron Sentimientos de Camino, Ultreia o Fe de Piedra, todas con una gran afluencia de público.

\subsubsection{EL PATROCINIO}

El patrocinio implica la entrega de dinero, u otros bienes o servicios a una actividad o evento por el cual se transmite un derecho de explotación comercial del mismo integrado por alguno de los tres elementos siguientes: exposición de la marca 
o empresa a la audiencia potencial de la actividad patrocinada, la explotación de la imagen asociada con dicha actividad, y la explotación comercial de diversas actividades derivadas del evento como la venta de productos, entradas, publicaciones, suministro de productos u otras explotaciones que puedan acordarse (BIGNE, 1998)

El objetivo principal que se persigue mediante el patrocinio de actividades y eventos es el de aprovechar la atención y repercusión de dichos acontecimientos para dar notoriedad e imagen al patrocinador. La gran cobertura que en muchos casos pueden llegar a recibir determinados eventos, especialmente los de carácter deportivo, supone una gran oportunidad para el refuerzo de la notoriedad, mediante la asociación entre la imagen del acontecimiento, individuo o equipo a patrocinar y la marca patrocinadora.

No debe confundirse el patrocinio con la publicidad, pues mientras que esta última posee una amplia dimensión comunicativa derivada de su capacidad para transmitir un mensaje específico, informativo o persuasivo; el patrocinio no ofrece ninguna información acerca de las características del producto, organización o evento excepto la de su nombre y logotipo.

El patrocinio está alcanzando niveles cada vez más importantes como herramienta de promoción del Xacobeo, centrándose gran parte de los esfuerzos en este campo. El deporte ha resultado un medio idóneo para la promoción del Xacobeo durante los últimos años; ya sea a través de campañas publicitarias específicas o por medio de la organización de diversas actividades promocionales que han tenido como marco al deporte.

La relación entre Xacobeo y deporte se inició con motivo del Año Santo de 1993: en el que el patrocinio de la Vuelta Ciclista a España de 1992 permitió el lanzamiento de la mascota Pelegrín y del emblema "Galicia Calidade", los cuales volvieron a estar presentes en la edición del año siguiente, cuyo final tuvo lugar en el emblemático Monte do Gozo en Santiago de Compostela. Un éxito promocional dado el amplio seguimiento logrado por parte de los medios de comunicación que, sin embargo, no ha tenido continuidad en años posteriores. Tan solo con motivo del Xacobeo 2004 se volvió a recurrir al ciclismo como herramienta de promoción mediante el patrocinio publicitario de la Vuelta Ciclista de Vehículos Clásicos, la cual no alcanzó la misma repercusión.

No obstante, tal vez el patrocinio deportivo que parece haberse mostrado más eficaz como mecanismo de comunicación del Xacobeo, haya sido el patrocinio de la Liga de Fútbol Profesional. Los acuerdos firmados permitieron la instalación de vallas publicitarias en todos los campos de fútbol de primera división, lo que contribuyó a familiarizar a millones de personas con la nueva imagen del Xacobeo diseñada en 1999. Asimismo, en ese mismo año, el Trofeo de Fútbol Xacobeo 99 que enfrentó en el estadio de San Lázaro de Santiago de Compostela al Real Madrid con el Real Club Celta de Vigo resultó ser muy eficaz promocionalmente. Y para el año 2004, además del patrocinio del campeonato, se logró que la selección Española de Fútbol visitase Santiago en su camino hacia Portugal para tomar parte en la Eurocopa 2004 
en una acción de relaciones públicas que atrajo el interés de los medios de comunicación que acompañaban al equipo español.

Otra buena relación de Xacobeo con el deporte es la de la vela y las actividades náuticas en general. Las diferentes competiciones de vela patrocinadas por el Xacobeo durante todas sus ediciones, entre las que cabe destacar el Trofeo de Vela Príncipe de Asturias, supusieron un importante respaldo en la difusión del turismo náutico en Galicia al mostrar las grandes posibilidades que las rías gallegas ofrecen para la práctica de este y otros deportes marítimos como la Copa del Mundo de Piragüísmo en 1993 o el Campeonato de España de Windsurfing en 2004.

En este mismo sentido, el golf también contribuyó a mostrar en todo el mundo las óptimas condiciones de las instalaciones gallegas para la práctica de este deporte a través del patrocinio del I Trofeo de Golf Xacobeo 99 que enfrentó en el campo de la Ría de Vigo a dos leyendas del golf como Severiano Ballesteros y el sudafricano Gary Player y que fue seguido en todo el mundo por trescientos millones de espectadores (XUNTA DE GALICIA, 2000, p. 60). De igual manera, la celebración del Trofeo Philips Challenge Xacobeo 99 reunió por primera vez en Galicia a figuras del golf nacional e internacional, lo que constituyó una gran oportunidad para integrar a Galicia en los circuitos mundiales de golf. Sin embargo, y a pesar de los importantes ingresos que la práctica del golf suele suponer para los lugares que acogen de manera habitual competiciones de este deporte, el patrocinio de torneos de golf fue abandonado como medio de promoción para el siguiente Xacobeo.

Una práctica deportiva que también es habitual en los Años Santos es la de actividades relacionadas con el mundo del motor como el Trial Indoor y el XXXII Rally de Ourense en 1999 o el Rally de San Froilán en 2004. Igualmente, la Carrera Pedestre Popular de Santiago de Compostela ha sido patrocinada por el Xacobeo en los tres últimos años.

Por último, otras disciplinas deportivas que también han contado con el patrocinio del Xacobeo a lo largo de sus distintas ediciones fueron el baloncesto, el voleibol femenino o carreras en globo. En 2004, se decidió ir un paso más allá en la relación del deporte con el Xacobeo mediante la concesión directa de ayudas económicas para la celebración de actividades deportivas como la concedida a la Fundación Arousa Cup, así como mediante la organización propia de eventos como fueron el II Campeonato de Espala de Tenis de Silla de Ruedas por Comunidades Autónomas.

En total más de 400 pruebas en las que el Xacobeo ha estado presente durante estos años, en estrecha colaboración con la Secretaría Xeral de Deportes de la Xunta de Galicia, en las que participaron grandes figuras del deporte mundial y que fueron seguidas, tanto "in situ" como por medio de la televisión, por millones de espectadores en todo el mundo. Un éxito tanto deportivo como promocional por el amplio seguimiento logrado por los medios de comunicación social y la consolidación de muchos deportes en la comunidad. 


\subsection{3.- COLABORACIÓN DEL SECTOR PRIVADO}

Además de recurrir al patrocinio de otras actividades y acontecimientos para darse a conocer, el Xacobeo, como gran evento cultural, es también objeto de patrocinio por parte de otras empresas que contribuyeron al éxito del programa de actividades organizadas con motivo del Año Santo. Es por lo tanto, al mismo tiempo, patrocinador y patrocinado.

El apoyo de las empresas patrocinadoras sirvió para respaldar económicamente la organización de la amplia gama de exposiciones, conciertos, congresos y actividades deportivas que tuvieron lugar con motivo del Año Santo y jugaron un importante papel en su difusión al incluir la marca identificativa del Xacobeo en sus propias campañas de publicidad en prensa, radio y televisión, contribuyendo de esta forma a hacer llegar la imagen del Xacobeo a miles de personas.

El patrocinio del Xacobeo por parte de empresas privadas se materializa mediante la firma de un convenio de patrocinio entre éstas y la Xunta de Galicia. La firma de estos convenios se adecua a la medida de cada una de las compañías aprovechando, en muchos casos, su propia estructura comercial y publicitaria, y en otros, diseñando actividades esponsorizadas por un patrocinador en exclusiva (XUNTA DE GALICIA, 2000 , p. 30). Según esto, se han firmado acuerdos con entidades de los más diversos sector, tales como empresas de transportes, medios de comunicación, bancos y, en general, entidades con una amplia presencia en todos los puntos de España.

La presencia de empresas patrocinadoras pertenecientes al sector turístico -considerando como integradoras de este sector a las compañías de transporte y a las agencias de viajes- ha estado presente de manera importante durante los tres últimos años. Las principales compañías de transporte españolas no quieren dejar pasar la oportunidad de aprovechar el flujo de clientes potenciales. Además, los convenios de colaboración con estas empresas permitieron la exhibición de la imagen del Xacobeo en todos los diferentes tipos de medios de transporte.

El patrocinio de empresas de otros sectores se ha ido consolidando con cada edición, especialmente en el caso de las entidades bancarias y de los medios de comunicación que hasta el Año Santo de 2004 no habían estado presentes en el Xacobeo, mientras que en dicho año dos grandes grupos de comunicación, cuatro periódicos y dos cadenas de radio fueron patrocinadores del evento conscientes del creciente interés y de la continua fuente de noticias que supone el conjunto de actividades que tienen lugar con motivo del Año Santo entre la población. El número de empresas patrocinadoras del sector de la alimentación también ha crecido cada año siendo en su mayoría empresas con sede en Galicia.

Dos empresas han estado presentes como patrocinadoras de forma continuada en los tres últimos Años Santos: Iberia y El Corte Inglés, la cual instaló además expositores con material informativo sobre el Camino de Santiago y las actividades del Xacobeo en todos sus centros comerciales de España.

Enrique Donaire, director general de Iberia, realizaba la siguiente valoración sobre su participación en el Xacobeo de 2004: “Llegado el final del Xacobeo 2004, desde 
Iberia nos congratulamos por su éxito, así como por la contribución que, desde esta compañía, hayamos podido hacer a su difusión y reconocimiento, al igual que ocurrió en las ediciones de 1993 y 1999, y como probablemente suceda de nuevo en 2010. Y es que, si algo ha caracterizado a Iberia a lo largo de sus 77 años de historia, es su respaldo incondicional a todos los grandes acontecimientos organizados en nuestro país, ya sean de tipo cultural, deportivo, turístico o cualquier otro, que ayuden a la proyección internacional y mejora de la imagen del Estado en su conjunto o de alguna de sus comunidades, ciudades o colectivos." (XUNTA DE GALICIA, 2005, p. 57).

Por último, además de las empresas patrocinadoras, la Xunta de Galicia ha firmado convenios con otra serie de compañías con la categoría de colaboradoras, y que también participaron en el desarrollo de la programación de actividades del Xacobeo. La mayoría de estas empresas colaboradoras son compañías gallegas, tales como Fadesa, Froiz, Mondariz o Pescanova; aunque también existen otras de fuera de Galicia.

\subsubsection{LAS RELACIONES PÚBLICAS Y LOS MEDIOS DE COMUNICACIÓN}

Existen múltiples definiciones sobre lo que son las relaciones públicas y su aplicación a diferentes ámbitos. La International Public Relations Association define las relaciones públicas como: "una función directiva de carácter continuativo y organizado, por medio de la cual organizaciones e instituciones públicas y privadas tratan de conquistar y mantener la comprensión, la simpatía y el apoyo de aquellos públicos con los que están o deberán estar vinculados a través de la evaluación de la opinión pública sobre la obra propia, a fin de concordar en todo lo posible las orientaciones y procedimientos propios y obtener por medio de una información amplia y difundida, una cooperación productiva y una realización más eficaz de los intereses comunes" (http://www.rrppnet.com.ar/fundamentosderrpp.htm).

Desde una óptica más orientada hacia el marketing, Miguel Ruiz establece que las relaciones públicas están vinculadas a la recogida y transmisión de actualidad por medio de noticias emitidas a través de cualquier medio. Las relacione públicas se llevan a cabo fomentando la generación de noticias y comunicaciones, realizando ruedas de prensa, presentaciones y demostraciones, patrocinando actos sociales, organizando conferencias, reuniones o otros actos que atraigan la atención de los medios de comunicación y de los públicos a los que se dirige con la finalidad de transmitir un mensaje favorable sobre el producto, empresa u organización que los promueve.

El atractivo de las relaciones públicas como herramienta de comunicación y de promoción reside en su alta credibilidad, la habilidad para captar la atención del público y la exageración. Los relatos y noticias suelen parecer más auténticos y creíbles para los lectores que los anuncios, permitiendo alcanzar al público que rehace a los vendedores y a la publicidad, además de poseer un alto potencial para destacar positivamente la imagen de una empresa o producto (KOTLER, et al, 2000, p. 633).

Muchos han sido los medios de comunicación, tanto nacionales como del extranjero, que durante estos años han dirigido su atención a Galicia y el Xacobeo, 
incluyendo noticias y reportajes de temática jacobea en revistas, radio y televisión; lo cual ha sido fundamental para dar a conocer la actividades culturales y festivas enmarcadas en la programación de la celebración del Año Santo y reforzar la implantación de la imagen del Xacobeo en todos los sectores de la sociedad.

Una rápida visita a las hemerotecas y archivos audiovisuales permite constatar como el Xacobeo y el Camino de Santiago fueron noticia casi a diario y objeto de numerosos especiales en las más variadas publicaciones; hasta el punto que la presencia de Galicia en los medios de comunicación de fuera de nuestras fronteras creció en un 1.400 por ciento durante los Años Santos (XUNTA DE GALICIA, 1994, P. 136).

El despliegue fue especialmente significativo en el caso de los grandes eventos del Xacobeo como la apertura de la Puerta Santa, que marca el inicio del Año Jubilar Compostelano, o la celebración del Día de Galicia el 25 de julio. También las numerosas actividades celebradas con motivo del Año Jubilar Compostelano recibieron la atención de los medios de comunicación, especialmente en el caso de los eventos deportivos y los conciertos. La revista francesa Méditerranée Magazine, por ejemplo, introducía del siguiente modo su reportaje Compostela, la peregrinación del siglo: "Europa comenzó a construirse a través del Camino de Santiago, afirmó Goethe. Una dimensión universal que toda Galicia reivindica aun con mayor intensidad con motivo del Año Jubilar. Músicos clásicos, estrellas del rock y del jazz se mezclan con los peregrinos" (XUNTA DE GALICIA, 2000, p. 63).

En el Día de Galicia, así como en la víspera y en días posteriores, buena parte de los principales diarios mundiales sitúan en sus páginas a la ciudad de Santiago de Compostela y a Galicia; y la mayoría de las grandes cadenas de radio y televisión españolas suelen realizar sus programas informativos desde la capital gallega.

E igualmente, muchos son los medios de comunicación que se hacen eco diariamente de la agenda de actividades del Xacobeo, con especial atención en el caso de la celebración de grandes eventos como el "Concerto dos Mil Anos" en 1993 o "A Festa dos Mundos" en 2004.

Un hecho que también en 2004 fue ampliamente recogido por los medios de comunicación en todo el mundo fue la concesión del premio Príncipe de Asturias de la Concordia, uno de los varios reconocimientos recibidos por el Camino de Santiago.

Pero las noticias relacionadas con el Xacobeo no son exclusiva de Galicia o Santiago, sino que todas las comunidades por las que transcurre la ruta jacobea son objeto de continuos reportajes sobre las peregrinaciones, iniciativas locales, conferencias o estudios sobre el Camino de Santiago; lo que contribuye aún más a difundir y extender los efectos dinamizadores del Xacobeo por todo el norte peninsular y otras regiones españolas y europeas por los que transcurre la ruta jacobea.

Asimismo, no todos los periodistas que se interesan por el Camino lo hacen en busca de un titular. Ellos mismos son noticia con motivo de su participación en diferentes congresos y simposios organizados con motivo del Xacobeo, o al visitar Santiago como auténticos peregrinos. De este modo, se ha visto a reporteros convertidos en caminantes, como el cronista de The New York Times David Duffy, quien 
recopiló sus experiencias a lo largo del Camino Francés en un reportaje titulado "Una recompensa para el peregrino, paso a paso".

$\mathrm{Y}$ es que la presencia en Compostela, desde la antigüedad, de grandes personalidades internacionales de la iglesia, la política, la cultura y la vida social a raíz de la celebración del Año Santo ha sido otro medio de promocionar el evento al atraer masivamente la atención de los medios de comunicación; de tal modo que se ha llegado a afirmar que la visita del Papa Juan Pablo II a Santiago en 1982 y en 1989 con motivo de la clausura de la IV Jornada Mundial de la Juventud fue la primera gran acción promocional del Xacobeo del año 1993.

Otros personajes destacados que han visitado la capital gallega, ya sea como peregrinos o en visita oficial, durante los últimos Años Santos han sido: los Reyes de España, Presidentes del Gobierno, etc.

Por otro lado, la ciudad de Santiago así como diversos puntos de la Ruta Jacobea, han servido de decorado de excepción para documentales, películas y series de televisión. De este modo, en 1999, las cámaras de la productora brasileña TV Globo recorrieron la Ruta Jacobea grabando un documental inspirado en la obra de Paulo Coelho "Peregrino a Compostela". En este mismo año, Antena 3 dedicó un capitulo completo de su serie de ficción "Compañeros" al Camino de Santiago, nombre este que a su vez recibió la serie de coproducción internacional, basada en una idea original del escritor Arturo Pérez Reverte para televisión, en la que participó esta misma cadena y que contó con la presencia de actores de fama mundial como Anthony Quinn, Charlton Heston, Anne Archer o Imanol Arias. Otra Película fue "La rosa de piedra" que Canal + estrenó el 25 de julio de 1999 y que tomaba como punto de partida un cuento del gallego Manuel Rivas. Y otro gallego, el dibujante Miguel Ánxo Prado, fue el encargado de crear a los personajes que acompañaron al popular Xabarín de la Televisión de Galicia (TVG) en sus aventuras a lo largo del Camino en el telefilme "Os vixilantes do Camiño". Finalmente, la colaboración entre la TVG, que incluyó en su programación diaria durante todo el año 2004 cortinillas publicitarias sobre el Xacobeo, y la cadena norteamericana CNN hizo posible que una decena de reportajes sobre el Año Jubilar llegaran vía satélite a telespectadores de cualquier punto del planeta; al igual que los canales internacionales de las cadenas de televisión españolas retransmitieron para toda Hispanoamérica las imágenes de los principales acontecimientos deportivos y culturales organizados con motivo del Xacobeo.

Por último, el Xacobeo también se sirve de las nuevas tecnologías como Internet, para difundir de manera internacional la actividad que realiza a través de su página Web www.xacobeo.es, que sirve de punto de información y de encuentro para millones de peregrinos de todo el mundo.

En conclusión, se puede afirmar que los medios de comunicación social desempeñan un papel fundamental en la promoción y difusión del Xacobeo. A partir de numerosos actos como inauguraciones, exposiciones, conciertos o por la presencia de personajes populares, los medios de comunicación difunden la imagen del Xacobeo y ofrecen informaciones sobre el Camino de Santiago, Galicia, los organismos encar- 
gados del Plan Xacobeo y del contenido de su programa; sin que todo ello suponga un coste directo para la Sociedade de Xestión do Xacobeo, pues como actuaciones de relaciones públicas, no suponen pago alguno a los medios de comunicación al contrario de lo que sucede con la publicidad.

\subsubsection{RELACIONES CON INSTITUCIONES DE LA SOCIEDAD CIVIL}

Junto con los apoyos del sector privado también se buscó para la promoción del Xacobeo, la colaboración de las instituciones públicas a través de la celebración de actos conjuntos de alta repercusión que generasen una amplia difusión por parte de los medios de comunicación social y que dada su reiteración e importancia merecen un comentario a parte.

El gobierno gallego estableció en 1993 contactos con diversos organismos con presencia internacional a fin de establecer lazos de comunicación con el exterior a través de los cuales divulgar y promocionar el programa del Xacobeo. Las embajadas, consulados y oficinas de turismo de España, desde sus sedes en el exterior, colaboraron a difundir el Camino de Santiago y el Xacobeo. Asimismo, los Centros Gallegos en el exterior realizaron una labor inestimable al acercar con entusiasmo la celebración del Año Santo a países de América, África y Oceanía. Algo semejante a lo que ocurrió con la Federación de Empresarios Gallegos en el Exterior (FEGAEX) que contribuyó, mediante diferentes actos, a la difusión del Xacobeo y de Galicia.

Otra manera de promover los intercambios con el exterior fue a través de las actividades culturales, musicales y festivas. En este sentido tuvieron lugar el Festival Internacional de Músicas del Camino, celebrado con motivo del Año Santo Compostelano de 1993 y que reunió en la ciudad de Lugo a más de tres mil músicos y a setenta grupos procedentes de toda España y Europa (XUNTA DE GALICIA, 1994, p. 106); el I Congreso Internacional de Gaitas, el Festival Internacional de la Canción del Camino y el intercambio cultural entre la ciudad gallega de Catoira, en la ruta jacobea de Arousa, y la danesa de origen viquingo de Frederikssund.

Por otro lado, expertos y estudiosos del Camino de Santiago en todo el mundo desempeñaron un importante papel mediante la creación de los llamados Comités Pro-Xacobeo para el fomento del conocimiento del Camino. La Consellería de Relacións Institucionais impulsó la creación del "Comité Internacional de Expertos del Camino de Santiago" como organismo consultivo asesor y cuyo presidente es el italiano Paolo Caucci.

Finalmente, los representantes del Xacobeo y, en general, las principales autoridades del gobierno de Galicia mantuvieron durante todo el año una activa presencia en diferentes países europeos vinculados al Camino de Santiago.

Las universidades gallegas también han contribuido, a distintos niveles, al éxito de la programación del Xacobeo mediante la organización de diversas reuniones y congresos que atrajeron a Galicia a numerosos e importantes investigadores y expertos de todo el mundo que hicieron de toda la comunidad gallega un marco 
de excepción para la investigación, intercambio y ampliación de conocimientos en torno a la ruta jacobea.

Finalmente, otras instituciones que también han supuesto un importante apoyo en la promoción del Xacobeo a lo largo de los últimos años han sido la Real Casa de Moneda y Timbre, el organismo de Loterías y Apuestas del Estado, el Instituto MAPFRE de Seguridad Vial, el Colegio Oficial de Arquitectos o la Asociación de Empresarios de Hostelería de Santiago.

\subsubsection{COLABORACIÓN CON INSTITUCIONES POLÍTICAS}

La colaboración de la Xunta de Galicia con otras instituciones españolas también resultó decisiva para la correcta difusión del Xacobeo. Los sucesivos planes diseñados para la gestión del Xacobeo dedicaron una especial atención a reforzar las relaciones con otras comunidades y regiones españolas por las que también transcurre el Camino de Santiago. A este fin respondió la organización, a lo largo de 1993 de unos Días Institucionales del Xacobeo que contaron con la asistencia de los presidentes de la práctica totalidad de las autonomías españolas a una serie de representaciones e intercambios culturales y festivos interregionales que sirvieron para llenar de vida y de color las calles de la ciudad del Apóstol y que atrajeron la atención de numerosos medios de comunicación. En recuerdo de estas comunidades, fueron bautizados los pabellones residenciales para peregrinos del Monte del Gozo en las afueras de la ciudad.

Este apoyo y respaldo de las comunidades autónomas a la celebración del Xacobeo continuó con motivo del Año Santo de 1999, en el que se volvieron a organizar de nuevo los Días Institucionales, una de cuyas actividades más simbólicas fue la plantación de un árbol ante el Pabellón de Galicia en San Lázaro de manos de las autoridades representativas de cada una de las autonomías.

Otro ejemplo de la colaboración de la Xunta de Galicia con otras instituciones fue el convenio-marco que el presidente de la Xunta y el Arzobispo de Santiago firmaron en diciembre de 1992 y por el cual se establecía, entre otras cuestiones, la cesión a la Iglesia del Centro Europeo de Peregrinacións e Pastoral Xuvenil Xoán Paulo II, así como la cooperación entre ambas instituciones en cuestiones referentes a la acogida de los peregrinos, la seguridad e información en la catedral y en actos culturales y publicaciones específicas (XUNTA DE GALICIA, 1994, p. 23).

\subsubsection{RECONOCIMIENTO INSTITUCIONAL: LA UNESCO Y EL PATRIMONIO MUNDIAL}

Si la promoción turística tiene como función fundamental la construcción social de una realidad turística en la mente de las personas, con unos lugares que tienen un significado especial, y las ansias por visitarlo, a través de una serie de pasos que son los procesos de exteriorización, objetivización e interiorización, el elemento más creíble de construcción turística es sin duda el que la UNESCO reconozca un determinado lugar como patrimonio mundial

De todas las promociones que se pueden realizar de cualquier lugar de turis- 
mo cultural, la más elevada es el nombramiento por la UNESCO como Patrimonio Mundial. Es el caso de Santiago de Compostela y el Camino de Santiago, que han sido declarados Patrimonio Mundial por la UNESCO:

\subsection{MATERIALES Y SUS CONTENIDOS}

\subsubsection{UNA IMAGEN PARA EL XACOBEO: MASCOTA Y LOGOTIPO}

Al igual que cualquier otro gran evento que desee promocionarse adecuadamente, comunicando una imagen de marca, el Xacobeo necesitaba disponer de una imagen característica que expresase las cualidades y valores del acontecimiento y que lo identificase a la perfección ante el público. Así fue como con motivo del año santo del año 1993, el diseñador gallego Luís Carballo elaboró un logotipo y una mascota para actuar de símbolos del evento.

La mascota se mantendría a lo largo del tiempo y continúa siendo un símbolo de identidad del Xacobeo que sustituye a las antiguas imágenes del camino de Santiago por un símbolo moderno. El logotipo se cambiaría con motivo del Xacobeo de 1999 y continuó en el 2004. Recientemente, debido a que la mascota y el logotipo ya no alcanzaban el reclamo originario, se decidió cambiarlos para el 2010.

\subsubsection{La mascota: El Pelegrín}

Pelegrín fue el nombre que recibió la mascota creada con motivo del Xacobeo del año 1993 y que se ha convertido en uno de sus símbolos más reconocidos y queridos. El diseño de la mascota evoca la tradicional figura del peregrino medieval, pero desde una perspectiva vanguardista y de modernidad.

La cabeza de Pelegrín recuerda a la forma del antiguo sombrero de aba alzada de dicha vestidura (XUNTA DE GALICIA, 1994, p. 20), con dos círculos blancos en forma de ojos, pero sin nariz ni boca. El cuerpo resulta de la su-

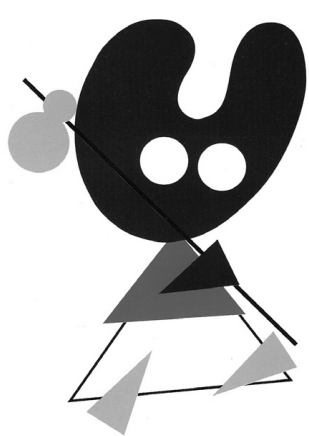
perposición de dos formas geométricas de colores blanco, rojo y azul a modo de túnica superpuesta por la esclavina, capa corta de cuero o tela que se llevaba suelta sobre otras prendas o que iba cosida al cuello de otra prenda más larga y que era la indumentaria más habitual entre los peregrinos medievales a Roma y Compostela. Las manos y los pies son triángulos con los que la figura sostiene el bastón del que cuelga la tradicional calabaza.

En definitiva, se trata de una figura sencilla de formas precisas y colores básicos, pero que comunica la sensación de amabilidad y acogida representativa de Galicia y de los gallegos, lo que le confirió a este personaje una gran popularidad durante el Xacobeo de 1993 permaneciendo desde entonces en la memoria de una gran parte de la sociedad, confirmándolo como mascota definitiva para todos los Años Santos venideros. 
Respecto al nombre que se le dio es de resaltar que fuese en gallego. Estamos en unos momentos en los que la lengua se convierte en una herramienta de identidad propia de Galicia que se debe de transmitir a todos los símbolos externos. Eso hará que sea irrepetible y específica.

Un tema fundamental a destacar son los colores y las formas. Dos elementos que han de servir para hacerle atractivo. El diseñador pretendió emplear formas atrevidas que nunca hasta ese momento se habían transmitido de un tema tan clásico como el Camino de Santiago. Estábamos en unos momentos de cambio y con la mascota se trataría de transmitir la nueva imagen de un tema tan histórico-religiosoclásico cultural.

En lo que respecta a las formas el autor recurrió a la utilización de formas simples y geométricas que ordenadas de modo intencional como las piezas de un simple puzzle diesen como resultado la imagen de un peregrino clásico. Combinación de lo tradicional a partir de una mentalidad moderna. Además de una imagen estática, parece que está en movimiento, al final quiso realizar un peregrino caminando, realizando la ruta Xacobea.

La inclusión de elementos geométricos planos para conseguir un diseño atrevido lo toma sin duda de McKight-Kauffer, el creador de un estilo con sencillos elementos geométricos, pero ordenados en un espacio muy cuidadosamente pensado que puede recordar algo y con colores planos e intensos. En definitiva, trata de conseguir imágenes simples pero con un diseño muy pensado que llega a parecer sofisticado si se analiza en profundidad. (SWANN, 1991, p. 14).

La agrupación la toma de la teoría de la gestalt, y de la idea de que nos guiamos por conocimientos previos para formar las imágenes: el ojo humano da forma a una serie de elementos, agrupándolos para reconocer algo en base a una serie de conocimientos previamente adquiridos

Respecto al color, aunque un mismo color puede significar cosas distintas para distintas personas e incluso para la misma persona en ambientes distintos o en momentos diferentes de su vida, existen una serie de aspectos que están relacionados con cada uno de los colores. Así, al analizar los colores incluidos en los logotipos y la mascota (Pelegrín) del Xacobeo, nos puede dar una idea de las emociones que se pretenden resaltar:

Rojo: es el color que recuerda lo ardiente. Lo más ardiente sería el rojo en su máxima saturación. Al ser ardientes parece el calor que sale de adentro hacia nosotros y por lo tanto reclama la atención. Es algo fuerte, agresivo y afecta a las personas aumentando la presión sanguínea y estimulando el sistema nervioso. Además, el rojo nos recuerda también a la sangre, que si se sitúa en el pecho de alguien remite al corazón.

Azul: es el color que recuerda el frío. Si los ardientes aumentaban la presión sanguínea y estimulaban el sistema nervioso, los fríos aminoran el metabolismo y nos llevan a la sensación de calma. También es símbolo de agua. 
Al colocar los colores ardientes y fríos juntos, la sensación que nos da es la de contraposición para hacernos vibrar, como si colocamos el fuego junto al hielo. Así, el Pelegrín nos atrae, nos vamos hacia él, pero debemos de tomar el camino con calma, al igual que la relación que se debe de establecer con el camino también ha de ser de cierta emoción, al entrar en un espacio cargado de energía, pero con serenidad que hace falta para reconciliarnos con nuestro espíritu.

Entre ambos, ardientes y fríos, están los cálidos y los frescos. Los cálidos se logran con la mezcla de amarillo al rojo y van degradando el rojo, pasando por el naranja hasta llegar al amarillo. Van desde el naranja rojizo, al naranja amarillento, pasando por el naranja. Parecen colores menos agresivos, más confortables y más acogedores, parece como si nos quisiéramos instalar en ellos.

Los colores frescos se logran mezclando amarillo al azul y van pasando desde el verde azulado al verde amarillento pasando por el verde. Nos recuerdan a la naturaleza, a la vegetación, a la primavera, a la renovación. Pero todo ello con la tranquilidad que se mezcla con cierta emoción de la naturaleza renovada cada primavera, que nos refresca al mismo tiempo que nos tienta. Quizás este sea el color que se nota en falta en el Pelegrín, máximo cuando estudiamos las motivaciones de los peregrinos que realizan el camino, que manifestaron en gran medida la preferencia por la naturaleza.

\subsubsection{Logotipos: 1993, 1999, 2004, 2010}

\section{Logotipo 1993}

El logotipo expresa de manera artística a partir del tradicional bastón del peregrino la cifra 93 correspondiente a la fecha del Año Santo. El bastón, también llamado bordón acaba en una voluta en su extremo superior izquierdo se asimila a un número nueve. De dicho extremo del bastón se acostumbraba a colgar una calabaza que contenía a modo de cantimplora la reserva de bebida para el viaje a Santiago y que dispuesta lateralmente representa el número tres. El logotipo se completa con las palabras Xacobeo y Galicia.

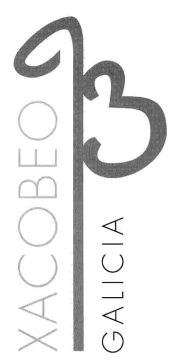

\section{Logotipo 1999-2004}

En el año 1999, el diseño de una nueva imagen corporativa que resultase innovadora fue una de las principales prioridades para la promoción y difusión del Xacobeo (XUNTA DE GALICIA, 2000, p. 45), lo que dio como resultado la creación de un nuevo y moderno logotipo, el cual ha logrado altas cuotas de popularidad junto a la ya para entonces familiar mascota Pelegrín.

El diseñador compostelano Alberte Permuy fue el

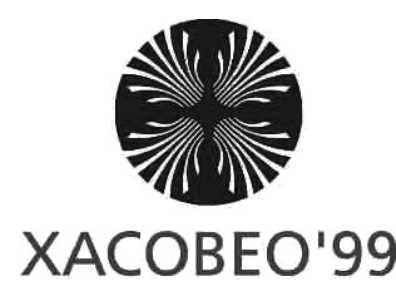

Galicia encargado de elaborar el nuevo logotipo inspirándose en la tradicional concha del peregrino, uno de los atributos más identificativos del camino de Santiago. 


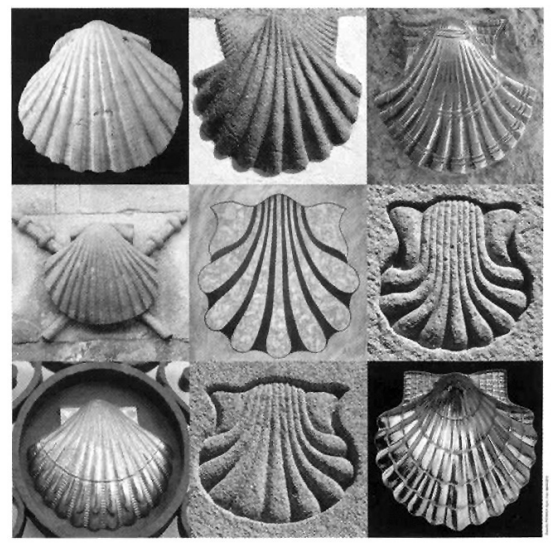

nus obra del sigo XII que constituye la primera guía del Camino de Santiago: "por lo mismo que los peregrinos que vienen de Jerusalén traen palmas, los que regresan del santuario de Santiago traen la concha. Pues bien, la palma significa el triunfo, la concha significa las obras buenas" (XUNTA DE GALICIA, 2000, p. 47).

La imagen para el Xacobeo 99 está formada por una moderna y estilizada concha de peregrino de color blanco repetida cuatro veces, enmarcadas dentro de un círculo de color rojo. El logotipo se completa con la denominación del evento y Galicia.

Para la elaboración de la vieira presente en el símbolo se partió de las conchas que decoran la capilla del Pilar de la catedral compostelana, una de las importantes aportaciones barrocas a la basílica apostólica, construida en los inicios del siglo XVIII bajo los auspicios del arzobispo Monroy.

La disposición en forma de aspa de las cuatro conchas se asemeja a unos brazos abiertos, transmitiendo una sensación de acogida y hospitalidad, cualidades que Galicia siempre posee con todo aquel que se acerca a visitarla, ya sea como peregrino o como un turista más. Del mismo modo, esta disposición dirige la mirada directamente hacia el centro del círculo, sugiriendo la idea de Santiago de Compostela como punto de encuentro de los diferentes caminos de peregrinación.

En definitiva, la sencillez y versatilidad del logotipo del Xacobeo 99 permitió su adaptación a los soportes más variados, figurando en la totalidad de actividades culturales, festivas y promocionales desarrolladas durante el Año Jubilar Compostelano, desempeñado en todo momento su papel de marca y su inmediata identificación con Galicia y el Xacobeo; lo que impulsó, al igual que sucediera en 1993 con el Pelegrín, la decisión de adoptarlo como símbolo permanente del Xacobeo para el 2004.

\section{Logotipo 2010}

Sin embargo, la imagen del Xacobeo, simbolizada fundamentalmente por la mascota del Pelegrín, según los resultados presentados por el gobierno, después de un período de alza en el 1993, que presidió la entrada en meta del pelotón de la vuelta ciclista a España, fue decayendo poco a poco. 
Según los datos oficiales presentados por el gobierno gallego el día 26 de mayo de 2006, "El último Xacobeo retrató el ocaso del icono que, en forma de pin, llegó a convertirse en accesorio usual en las solapas de las americanas de los conselleiros y alcaldes. Los números cantan. En 1993, la Xunta recaudó 600.000 euros por los derechos de imagen

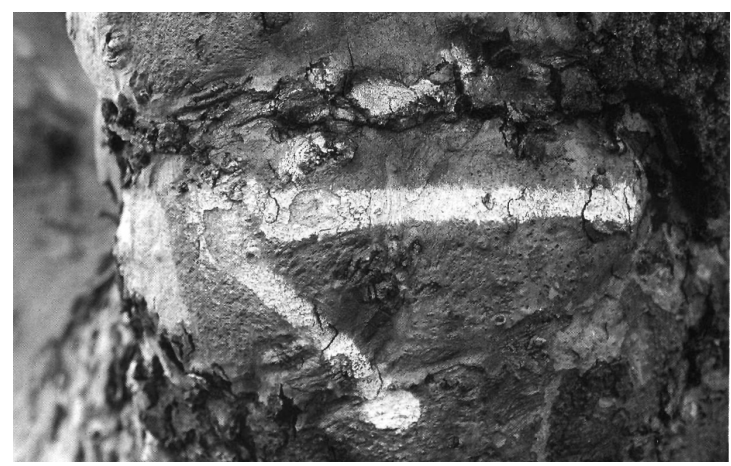
de los 108 productos que se comercializaron entonces con la imagen del Pelegrín. Sólo el permiso de pins reportó 150.000 euros. ${ }^{3}$ Once años después, en el caso del año santo de 2004, la recaudación de la Xunta quedó en 90.000 euros. En 1993, concurrieron 64 empresas, y en el 2004, sólo seis" (LA VOZ DE GALICIA, 2006, p. 14).

Para ello se propone un nuevo logotipo que sustituye a todo lo anterior. Después de un concurso, al que concurrieron 19 empresas, fue ganado por la empresa Océano Visión que dirige Nacho Cao. El nuevo logotipo consiste en una reinterpretación de la flecha amarilla, universalmente vinculada al Camino de Santiago desde que un párroco de O Cebreiro (Lugo), a falta de ayudas oficiales recorrió el Camino Francés con su coche cargado de botes de pintura amarilla, y así fue pintando flechas amarillas para orientar a los peregrinos.

Así, la nueva imagen consiste en una flecha conformada a base de puntos de color amarillo, salvo el de la punta que es azul. Este punto azul simboliza el anhelado lugar de encuentro del peregrino cuando inicia el Camino que es llegar a Santiago de Compostela.

Además de la flecha que se pintó por parte del mencionado párroco para orientar a los peregrinos, nosotros también podemos ver en ella los recuerdos de la constelación de estrellas que guiaron al ermitaño para localizar los restos del Apóstol Santiago, según la tradición y que dieron nombre a Compostela (campo de estrellas).

Los colores que emplea son el azul que da la calma con la que se ha de entrar en Santiago, además el azul recuerda la lluvia y Santiago es un lugar que se identifica con la lluvia, una lluvia tranquila, benigna no torrencial y maligna como en otros lugares.

El amarillo es la alegría con la que se ha de recorrer el camino. No empleó sin embargo colores rojos que serían demasiado ar-
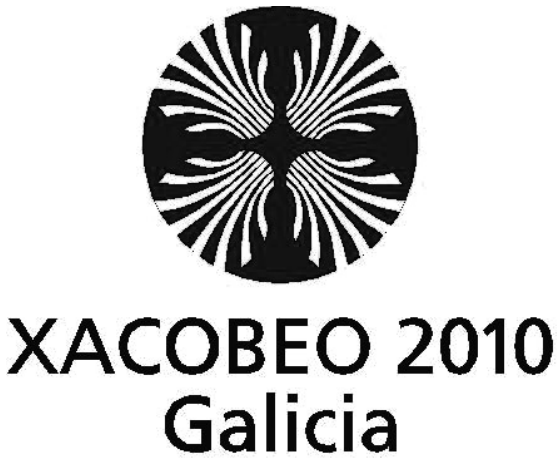

3 Otros objetos fueron camisetas, bolígrafos, paraguas, etc. 
dientes. Tampoco empleó el verde que está relacionado con la naturaleza y presente en las motivaciones de muchos peregrinos, motivo por el que nosotros recomendamos que se emplee en algún momento posible.

Con la llegada del nuevo gobierno del PP, para el Xacobeo de 2010 se abandona este logo y se retoma el anterior basado en la concha, pues se cree que ya es muy conocido a nivel mundial y eso favorecerá la promoción.

\subsubsection{LIBROS: BIBLIOGRAFÍA SOBRE EL XACOBEO}

Además de lo que son las actividades explícitas de promoción del camino que tienen una función fundamentalmente persuasiva, en torno al Camino de Santiago se desarrolló una gran labor de promoción mediante manuales que se convirtieron en punto de información sobre el Camino y sobre la forma de realizarlo que pueden ser considerados auténticos manuales de promoción del Camino. Estos manuales tuvieron su comienzo en el Codex Calixtinus $^{4}$ que data de los primeros tiempos (siglo XII).

\subsubsection{FOLLETOS}

Se realizaron folletos en múltiples lenguas (gallego, castellano, inglés, francés, alemán,..) que se distribuyeron en los diferentes lugares de promoción. Además de folletos generales sobre el Camino de Santiago, también se realizaron folletos específicos sobre los distintos Caminos y distintos temas. En lo que sigue vamos a analizar el contenido de uno de ellos, el que figura en la página de Turgalicia en estos momentos y nos da una idea del contenido de los folletos en general, los cuales no son folletos que tengan una función fundamentalmente emotiva, sino que están más bien pensados como folletos descriptivos de la realidad del Camino.

\subsubsection{GUÍAS, CREDENCIAL Y COMPOSTELA}

Las guías constituyen una de las formas de promoción de cualquier lugar turístico. Aquí nos interesa analizar sin embargo el contenido de las guías a Santiago de Compostela que sirven para orientar al peregrino sobre la realización desde los cánones de la peregrinación recurriendo a las prácticas de autenticidad desde la perspectiva más profunda del Camino.

Existen multitud de guías, algunas de carácter general y otras que son específicas de colectivos como por ejemplo discapacitados que no pueden hacer los recorridos con los tramos habituales.

En estas guías en general se orienta sobre las condiciones materiales y espirituales que ha de seguir el peregrino para poder realizar el camino de forma "auténtica" y de la recompensa que ha de tener por ello. Además de las condiciones materiales de diverso tipo como vestimenta y otros utensilios, y de las condiciones físicas, también

4 Códice Calixtino (siglo XII). Otros nombres que recibió fueron: Iacobus, Liber Sancti Iacobi, Codex Sancti Iacobi, Codex Calixtinus... Consiste en una compilación de textos jacobeos. Se realizó bajo el papado de Calixto II (1119-1124), de ahí el nombre de Calixtino. No se sabe bien quién realizó la compilación, pero está referido en su integridad a los avatares de la peregrinación y al culto a Santiago. Se divide en cinco libros. 
se informa de los requisitos que ha de seguir para hacer el camino de forma espiritual y de las pruebas y documentos que ha de portar a la ida y el regreso.

En su conjunto el proceso que proponen estas guías se puede resumir en la estructura de los ritos de paso de cualquier proceso iniciático-ritual. Para controlar la entrada en el paraíso Dios puso a los querubines, y el acceso solo se le concede a aquellas personas que van preparadas, además deben de seguir unos determinados cauces o caminos que llevan a su purificación y por lo tanto a su entrada. Lo mismo ocurre con los paraísos turísticos, siendo necesario seguir todo un proceso que nosotros analizamos desde la perspectiva fenomenológica-etnometodológica, y se adapta tanto a lo que puede ser un paraíso histórico-cultural, como un paraíso natural, una práctica deportiva-riesgo, etc. Tomemos como ejemplo el de la peregrinación.

El proceso que se sigue para la entrada en el paraíso consiste en el paso por una serie de ritos -ritos de paso- ${ }^{5}$ que aunque son diferentes para cada tipo de turismo y para cada lugar de atracción concreto, a nivel formal todos ellos coinciden. Gennep diferencia tres pasos distintos que son la separación del mundo cotidiano, el limen y la agregación

\section{IMAGEN PROYECTADA, RECURSOS TURÍSTICOS (REALIDAD), IMA- GEN CONFORMADA PREVIA E IMAGEN PERCIBIDA A POSTERIORI DE LOS TURISTAS}

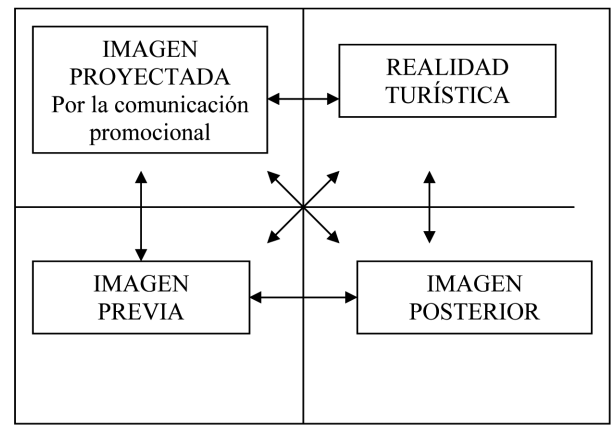

Los resultados de nuestro análisis fueron que en general los turistas que visitan Santiago de Compostela no lo hacen debido a una publicidad impulsiva, sino porque después de informarse deciden hacer el camino para tener una vivencia que esperan encontrar de forma relajada. Coinciden en que la imagen que se proyecta del Camino es precisamente la de proporcionar esa información y si fuese de otro tipo más impulsiva -como en otros lugares turísticos-, perdería la identidad.

Creen en general que la imagen proyectada se queda escasa comparada con la realidad del Camino, no sólo por los objetos materiales que se encuentran, sino sobre todo por las vivencias que se tienen en el Camino y que son imposibles en cualquier otro lugar de turismo. 
La imagen previa que se habían realizado del Camino para nada coincide con la realidad vivida. Aquí sí que es cierto ese lema de que el turista siempre espera encontrar lo inesperado, pero en este caso multiplicado de forma geométrica.

La imagen posterior que se llevan del Camino es muy distinta de la que se habían formado previamente, y normalmente se quedan sin palabras para explicarla. En todo caso se puede realizar un buen análisis a través de los escritos en los libros que existen en ciertos lugares por donde pasan.

\section{REFERENCIAS BIBLIOGRÁFICAS}

BIGNÉ, J.E (1998): "El patrocinio de acontecimientos. Una revisión conceptual”. Boletín Económico del ICE, n ${ }^{\circ} 2591$, págs. 19-25

BIGNÉ ALCAÑIZ, A; FONT ARLET, X.; ANDREU SIMÓ, L. (2000): Marketing de destinos turísticos. Análisis y estrategias de desarrollo, Madrid, ESIC Editorial

EJARQUE, J. (2005): Destinos turísticos de éxito. Diseño, creación, gestión y marketing, Madrid, Pirámide.

EVANS, P. (1997): State-Society Synergy: Government and Social Capital in Development, Berkeley, University of California at Berkeley.

GARCÍA-ABRIL, G. (1999): "Evanxelización e promoción turística nas peregrinacións a Santiago”, en Antón Álvarez Sousa (dir.), Homo Peregrinus, Vigo, Xerais, pp. 153-175.

GENNEP, A. Van (1986): Los ritos de paso, Madrid, Taurus.

KOTLER,P., CÁMARA D., GRANDE I., CRUZ I., (2000): Dirección de Marketing, Madrid, Edición del Milenio.

LEIRA LÓPEZ, J. (1999): "As Asociacións de Amigos do Camiño de Santiago. O seu discurso social", en Antón Álvarez Sousa (dir.), Homo Peregrinus, Vigo, Xerais, pp. 129-152

MILLS, W. (1987): La imaginación sociológica, México, Fondo de Cultura Económica.

RODRÍGUEZ, J. C. (1996): "Perspectiva histórica de las Asociaciones. Su relación con las Cofradías, instituciones civiles y eclesiásticas. Reflexiones sobre las actividades más relevantes de las Asociaciones", en Anden los que sepan, sepan los que andan, Actas del Congreso Xacobeo, Pamplona, 1-13 de abril de 1996

SWANN, A. (1991): Diseño y marketing, Barcelona, Gustavo Gili.

XUNTA DE GALICIA (1994): Plan Xacobeo 93, Santiago de Compostela, Xunta de Galicia.

XUNTA DE GALICIA (2000): Xacobeo 99, Santiago de Compostela, Xunta de Galicia.

XUNTA DE GALICIA (2005): Xacobeo 04, Santiago de Compostela, Xunta de Galicia 